\title{
Práticas de gestão da cadeia de suprimentos e seus eventuais relacionamentos com as prioridades competitivas da produção: evidências empíricas do setor eletroeletrônico à luz de modelagem de equações estruturais
}

\author{
Ana Beatriz Lopes de Sousa Jabbour ${ }^{\text {** }}$, Alceu Gomes Alves Filho ${ }^{\text {, }}$ \\ Adriana Backx Noronha Viana ${ }^{\mathrm{c}}$, Charbel José Chiappetta Jabbour ${ }^{\mathrm{d}}$ \\ a*ablsjabbour@gmail.com, UNESP, Brasil \\ balceu@dep.ufscar.br, UFSCar, Brasil \\ cbackx@usp.br, USP, Brasil \\ dprof.charbel@gmail.com, UNESP, Brasil
}

\begin{abstract}
Resumo
Este artigo tem como objetivo identificar as práticas de gestão da cadeia de suprimentos que estão sendo adotadas no setor eletroeletrônico brasileiro e verificar se as prioridades competitivas da produção das empresas desse setor se relacionam com a adoção de tais práticas. Desenvolveu-se uma pesquisa empírica, de cunho quantitativo, a partir da realização de uma pesquisa survey por e-mail com gerentes de empresas do setor eletroeletrônico da Associação Brasileira da Indústria Elétrica e Eletrônica. Técnicas estatísticas descritivas e multivariadas de segunda geração (modelagem de equações estruturais) foram empregadas para analisar os dados obtidos. Como principais resultados deste artigo destacam-se: a) as práticas de gestão da cadeia de suprimentos que estão sendo mais implantadas são voltadas à integração e apoio das atividades de desenvolvimento de produtos com os clientes; e b) não foram verificadas relações significativas entre as prioridades competitivas das empresas estudadas e a adoção de práticas de gestão da cadeia de suprimentos.
\end{abstract}

Palavras-chave

Práticas de gestão da cadeia de suprimentos. Prioridades competitivas. Setor eletroeletrônico.

\section{Introdução}

0 tema gestão da cadeia de suprimentos (SCM) é cada vez mais recorrente nas discussões acadêmicas e empresariais e vem sendo debatido desde o início da década de 1990 (HARLAND, 1997; LUMMUS; VOKURKA, 1999; LAMBERT; COOPER, 2000; MENTZER et al., 2001; TAN, 2002; PIRES, 2004; PRAMATARI, 2007; MELNYK et al., 2008; ARSHINDER; DESHMUKH, 2008).

Uma forma de verificar a adoção da abordagem SCM nas organizações se dá a partir do uso de suas práticas de gestão (JABBOUR, 2009). Segundo
Basnet et al. (2003), há necessidade de trabalhos empíricos sobre práticas de SCM, uma vez que há escassez de trabalhos publicados e um vasto campo de pesquisa a ser explorado. Há algumas iniciativas de propor constructos referentes a práticas de SCM, como as de Tan, Lyman e Wisner (2002) e de Li et al. (2005).

A literatura sobre práticas de SCM trata, em geral, sobre como a implementação das práticas melhora a vantagem competitiva e o desempenho operacional e organizacional (LAMBERT; COOPER; 
PAGH, 1998; TAN; LYMAN; WISNER, 2002; TAN, 2002; Ll et al., 2005, 2006; KOH et al., 2007; ROBB; XIE; ARTHANARI, 2008; CHOW et al., 2008; HSU et al., 2009; MARTIN; PATTERSON, 2009). A maioria desses artigos identificados não distingue a implantação das práticas conforme o porte da empresa, a posição na cadeia, o setor produtivo, o tipo de produto, bem como não consideram a estratégia de produção da empresa como fator relevante e que influencia a adoção de práticas de SCM, uma vez que cada uma dessas variáveis pode representar uma realidade diferente.

No entanto, segundo Hsu et al. (2009), as tentativas de implementar práticas de SCM não têm sido universalmente bem sucedidas e isso pode ser entendido pela falta de visão sobre a relação entre práticas de SCM e outros elementos do portfólio da capabilidade operacional. Zhao e Lee (2009) entendem como capabilidades operacionais as prioridades competitivas (PC) da produção (custo, qualidade, flexibilidade e entrega), que são a competência da função produção para apoiar a estratégia da empresa.

Salles et al. (2010) realizaram um estudo comparativo entre cadeias automotivas do Brasil e da Espanha e constataram que as PC das montadoras condicionam fortemente as PC dos fornecedores. Vachon, Halley e Beaulieu (2009) também utilizaram as PC para verificar o alinhamento na cadeia de suprimentos (SC) a partir do relacionamento com fornecedores. Maia, Cerra e Alves Filho (2005) estudaram empresas do setor automotivo do Brasil e identificaram interrelações entre as escolhas das PC e a forma de gerir a SC. Demeter, Gelei e Jenei (2006) constataram que a estratégia da empresa focal é fortemente relacionada à configuração da SC e ao uso de práticas de SCM.

Considerando que práticas de SCM é uma das formas possíveis de estudo da SCM, tema atual e relevante nas discussões acadêmicas e empresariais e que as pesquisas até então empreendidas sobre práticas de SCM não tratam claramente sobre determinados aspectos que podem afetar a sua adoção, e que as PC tendem a influenciar, ou ter alguma interrelação com SCM. Então podem-se expressar as inquietações que motivaram esta pesquisa: Quais são as práticas de SCM que estão sendo adotadas no setor eletroeletrônico brasileiro? As prioridades competitivas da produção das empresas desse setor se relacionam com a adoção de práticas de SCM? Portanto, os objetivos da pesquisa são: a) identificar as práticas de SCM adotadas no setor eletroeletrônico brasileiro; e b) verificar se as prioridades competitivas das empresas desse setor se relacionam com a adoção de práticas de SCM.

Esta pesquisa realizou uma survey com empresas do setor eletroeletrônico do Brasil para atingir os objetivos postos. 0 setor eletroeletrônico do Brasil foi escolhido como objeto de estudo pela sua importância na economia do país (4\% do PIB, ASSOCIAÇÃO..., 2009) e pelas características: ser um setor dependente em termos de importação de matérias-primas do exterior; não deter internamente as competências necessárias para produzir circuitos integrados, impactando na competitividade do setor; e por não introduzir independentemente novos projetos de produtos, cabendo às empresas instaladas no Brasil fazer adaptações nos projetos de sua matriz multinacional. Portanto, o setor possui um conjunto de características já conhecidas em sua SC que podem ajudar a interpretar o comportamento das empresas quanto à adoção de práticas de SCM.

As próximas seções deste artigo se destinam a discutir a literatura pertinente sobre prioridades competitivas da produção e práticas de SCM (seção 2); apresentar os procedimentos metodológicos adotados para consecução da survey (seção 3); destacar os principais resultados da pesquisa (seção 4); discutir os indicativos dos resultados (seção 5); e, por fim, ressaltar as conclusões e as limitações deste estudo (seção 6).

\section{Revisão da literatura}

\subsection{Prioridades competitivas}

Segundo Skinner (1969), as PC estão relacionadas a critérios de desempenho competitivo que a função produção pode adotar para se adequar à estratégia de negócios da organização. Dependendo da forma escolhida pela empresa para atender aos requisitos de mercado, a organização orienta, a partir das PC, como a função produção desempenhará suas operações (SLACK; LEWIS, 2003).

Consideram-se como elementos representativos das PC: custo, qualidade, flexibilidade e entrega. Apesar de haver outras possíveis PC, escolheram-se essas quatro tendo em vista o esforço de sistematização realizado por Jabbour (2009), que elencou as PC utilizadas entre mais de 40 artigos nacionais e internacionais e constatou que essas são as mais usuais nas pesquisas acadêmicas.

As características que compõem cada uma das PC estão no Quadro 1.

Pela teoria top down do conteúdo da estratégia de produção, as PC afetam as áreas de decisões da manufatura e uma dessas é a área estrutural integração vertical (VOSS, 1995). Essa área está relacionada à forma como a empresa lida com a internalização das operações de produção e o quanto ela direciona as mesmas a seus fornecedores e clientes (RUDBERG; 
Quadro 1. Caracterização das PC.

\begin{tabular}{|c|c|c|}
\hline Prioridade competitiva & Característica & Autores \\
\hline \multirow{2}{*}{ Custo } & $\begin{array}{l}\text { Oferecer produtos com menor preço que os } \\
\text { competidores. }\end{array}$ & $\begin{array}{c}\text { Vokurka e Davis (2004), Urgal-González e } \\
\text { García-Vázquez (2007), Dangayach e Deshmukn (2006) }\end{array}$ \\
\hline & Reduzir custos de produção. & $\begin{array}{l}\text { Ward e Duray (2000), Martín-Peña e Díaz-Garrido } \\
\text { (2008), Wang e Cao (2008) }\end{array}$ \\
\hline \multirow{4}{*}{ Qualidade } & $\begin{array}{l}\text { Oferecer produtos com características e funcionalidades } \\
\text { que são superiores às dos ou não disponibilizadas pelos } \\
\text { competidores. }\end{array}$ & $\begin{array}{c}\text { Garvin (1993), Kim e Arnold (1996), Vokurka e } \\
\text { Davis (2004), Dangayach e Deshmukn (2006), } \\
\text { Urgal-González e García-Vázquez (2007), Martín-Peña } \\
\text { e Díaz-Garrido (2008) }\end{array}$ \\
\hline & $\begin{array}{l}\text { Oferecer produtos fabricados de acordo com padrões } \\
\text { pré-estabelecidos. }\end{array}$ & $\begin{array}{l}\text { Garvin (1993), Urgal-González e García-Vázquez } \\
\text { (2007), Martín-Peña e Díaz-Garrido (2008) }\end{array}$ \\
\hline & Oferecer produtos com baixa taxa de defeitos. & $\begin{array}{l}\text { Kim e Arnold (1996), Martín-Peña e Díaz-Garrido } \\
\text { (2008) }\end{array}$ \\
\hline & Oferecer produtos duráveis. & Kim e Arnold (1996); Dangayach e Deshmukn (2006) \\
\hline \multirow{5}{*}{ Flexibilidade } & Implementar mudanças rápidas em projeto de produto. & $\begin{array}{c}\text { Garvin (1993), Kim e Arnold (1996), Vokurka e } \\
\text { Davis (2004), Dangayach e Deshmukn (2006), } \\
\text { Urgal-González e García-Vázquez (2007), Martín-Peña } \\
\text { e Díaz-Garrido (2008) }\end{array}$ \\
\hline & Implementar mudanças rápidas no mix de produtos. & $\begin{array}{l}\text { Garvin (1993), Kim e Arnold (1996), Dangayach e } \\
\text { Deshmukn (2006), Urgal-González e García-Vázquez } \\
\text { (2007), Martín-Peña e Díaz-Garrido (2008) }\end{array}$ \\
\hline & $\begin{array}{l}\text { Introdução rápida de novas versões de produtos } \\
\text { existentes, ou produtos totalmente novos. }\end{array}$ & $\begin{array}{c}\text { Kim e Arnold (1996), Vokurka e Davis (2004), } \\
\text { Urgal-González e García-Vázquez (2007), Martín-Peña } \\
\text { e Díaz-Garrido (2008) }\end{array}$ \\
\hline & Oferecer ampla gama de produtos. & $\begin{array}{l}\text { Kim e Arnold (1996), Urgal-González e García-Vázquez } \\
\text { (2007), Martín-Peña e Díaz-Garrido (2008) }\end{array}$ \\
\hline & $\begin{array}{l}\text { Mudanças rápidas nos volumes de produção em } \\
\text { resposta à mudança da demanda. }\end{array}$ & $\begin{array}{l}\text { Garvin (1993), Kim e Arnold (1996), Dangayach e } \\
\text { Deshmukn (2006), Urgal-González e García-Vázquez } \\
\text { (2007), Martín-Peña e Díaz-Garrido (2008) }\end{array}$ \\
\hline \multirow[t]{2}{*}{ Entrega } & Menor tempo de entrega possível. & $\begin{array}{c}\text { Garvin (1993), Vokurka e Davis (2004), Dangayach e } \\
\text { Deshmukn (2006), Urgal-González e García-Vázquez } \\
\text { (2007), Martín-Peña e Díaz-Garrido (2008), Wang e } \\
\text { Cao (2008) }\end{array}$ \\
\hline & $\begin{array}{c}\text { Atender aos pedidos nas datas e nas quantidades da } \\
\text { entrega planejada. }\end{array}$ & $\begin{array}{l}\text { Garvin (1993), Dangayach e Deshmukn (2006), } \\
\text { Urgal-González e García Vázquez (2007), Wang e Cao } \\
\text { (2008) }\end{array}$ \\
\hline
\end{tabular}

OLHAGER, 2003). Portanto, as PC tendem a influenciar no grau de integração (ou desintegração) vertical, ou seja, as PC tendem a ter algum relacionamento com questões relativas à $\mathrm{SC}$ - processos integrados entre fornecedores e clientes (PIRES; SACOMANO NETO, 2010).

Salles et al. (2010) realizaram um estudo comparativo entre cadeias automotivas do Brasil e da Espanha e constataram que as PC das montadoras condicionam fortemente as PC dos fornecedores. Vachon, Halley e Beaulieu (2009) também utilizaram as PC para verificar o alinhamento na SC, a partir do relacionamento com fornecedores. Maia, Cerra e Alves Filho (2005) estudaram empresas do setor automotivo do Brasil e identificaram interrelações entre as escolhas das PC e a forma de gerir a SC.

Portanto, diante do exposto, há indícios de que as PC de uma empresa podem afetar a sua SCM e, sendo assim, podem afetar também a adoção de práticas de SCM.

\subsection{Práticas de gestão da cadeia de suprimentos}

Li et al. $(2005,2006)$ definem práticas de SCM como um conjunto de atividades conduzidas por organizações para promover uma gestão eficiente de sua SC. Para Pires (2004), as práticas de SCM estão relacionadas a iniciativas para mudar a forma de fazer e gerenciar os processos de negócios ao longo de SC. Vaart e Donk (2008) afirmam que práticas de SC são consideradas atividades tangíveis, ou tecnologias que exercem um importante papel na colaboração da empresa focal com seus fornecedores e clientes.

Há diferentes formas para classificar as diversas práticas de SCM, mas, segundo Tan (2002), Tan, Lyman e Wisner (2002), li et al. (2005, 2006), Zhou e Benton Junior (2007), Koh et al. (2007), Robb, Xie e Arthanari (2008), Chow et al. (2008), Hsu et al. (2009) e Martin e Patterson (2009), todas resultam na intenção da melhoria do desempenho operacional. 
0 Quadro 2 apresenta uma sistematização das principais práticas de SCM.

Cada classificação possui um conjunto de práticas relativas às suas perspectivas conceituais. Olhager e Selldin (2004) caracterizam a integração da SC como a habilidade da empresa conseguir coordenar os outros integrantes da cadeia de forma a obter a colaboração deles na previsão de demanda, planejamento de capacidade, planejamento de estoque e de produção. Para Li et al. (2005), o compartilhamento de informações refere-se à extensão com que informações críticas ou corriqueiras são compartilhadas com outros membros da cadeia de suprimentos. A gestão de serviço ao cliente pretende identificar reclamações dos clientes, manter relacionamentos de longo prazo e aprimorar a satisfação dele. A postergação visa encaminhar uma ou mais operações para as últimas etapas da SC, a fim de contornar eventuais alterações de programação e permitir flexibilidade na produção. Chow et al. (2008) descrevem o relacionamento com cliente e com fornecedor como uma forma de melhorar os canais de informação, a partir da colaboração de ambos com a empresa focal, como uma forma de apoio às decisões de suprimentos do fornecedor (ajuda em termos de facilitar negociações em função do poder de barganha) e de compartilhamento de informações sobre programação e desenvolvimento de novos produtos.

A adoção das práticas de SCM não é uniforme ao longo de toda uma cadeia. A literatura aponta alguns condicionantes e variáveis de influência como, por exemplo, a estratégia de produção da empresa. Robb, Xie e Arthanari (2008) apontam que as PC são elementos mediadores na análise do impacto das práticas de SCM no aumento do desempenho organizacional. Demeter, Gelei e Jenei

Quadro 2. Sistematização das principais práticas de SCM.

\begin{tabular}{|c|c|c|}
\hline Classificação & Práticas associadas & Autores \\
\hline \multirow{6}{*}{ Práticas de integração de SC } & $\begin{array}{l}\text { Promover a integração das atividades ao } \\
\text { longo da SC. }\end{array}$ & $\begin{array}{l}\text { Tan (2002), Tan, Lyman e Wisner (2002), } \\
\text { Basnet et al. (2003), Hsu et al. (2009) }\end{array}$ \\
\hline & Reduzir o tempo de resposta ao longo da SC. & $\begin{array}{l}\text { Tan (2002), Tan, Lyman e Wisner (2002), } \\
\text { Chow et al. (2008), Hsu et al. (2009) }\end{array}$ \\
\hline & $\begin{array}{c}\text { Estabelecer contatos mais frequentes com os } \\
\text { integrantes da SC. }\end{array}$ & $\begin{array}{c}\text { Tan (2002), Tan, Lyman e Wisner (2002), } \\
\text { Basnet et al. (2003) }\end{array}$ \\
\hline & $\begin{array}{l}\text { Envolver a SC em planos de produtos/ } \\
\text { serviços/marketing. }\end{array}$ & $\begin{array}{l}\text { Tan (2002), Tan, Lyman e Wisner (2002), } \\
\text { Olhager e Selldin (2004), Basnet et al. (2003) }\end{array}$ \\
\hline & $\begin{array}{l}\text { Obter a colaboração dos integrantes da SC } \\
\text { quanto à previsão de demanda/planejamento } \\
\text { de estoque/planejamento de produção. }\end{array}$ & Olhager e Selldin (2004) \\
\hline & $\begin{array}{l}\text { Criar uma equipe de SCM que inclua } \\
\text { elemenetos de outras empresas. }\end{array}$ & Basnet et al. (2003), Chow et al. (2008) \\
\hline \multirow{5}{*}{ Práticas de compartilhamento de informações } & Compartilhar informações informalmente. & $\begin{array}{l}\text { Tan (2002), Tan, Lyman e Wisner (2002), } \\
\text { Basnet et al. (2003), Chow et al. (2008) }\end{array}$ \\
\hline & Compartilhar informações formalmente. & $\begin{array}{l}\text { Tan (2002), Tan, Lyman e Wisner (2002), } \\
\text { Basnet et al. (2003), Hsu et al. (2009) }\end{array}$ \\
\hline & $\begin{array}{l}\text { Participar do esforço de marketing dos } \\
\text { clientes. }\end{array}$ & Tan (2002); Basnet et al. (2003) \\
\hline & $\begin{array}{c}\text { Determinar as necessidades futuras dos } \\
\text { clientes. }\end{array}$ & $\begin{array}{l}\text { Tan (2002), Tan, Lyman e Wisner (2002), } \\
\text { Basnet et al. (2003), Chow et al. (2008) }\end{array}$ \\
\hline & $\begin{array}{l}\text { Comunicar as estratégias futuras aos } \\
\text { fornecedores. }\end{array}$ & $\begin{array}{l}\text { Tan, Lyman e Wisner (2002), Basnet et al. } \\
\text { (2003), Chow et al. (2008), Hsu et al. (2009) }\end{array}$ \\
\hline \multirow{2}{*}{ Práticas de gestão de serviço ao cliente } & Entregar direto no ponto de consumo. & $\begin{array}{l}\text { Tan (2002), Tan, Lyman e Wisner (2002), } \\
\text { Basnet et al. (2003), Chow et al. (2008) }\end{array}$ \\
\hline & Obter feedback dos clientes finais. & $\begin{array}{l}\text { Tan (2002), Tan, Lyman e Wisner (2002), } \\
\text { Basnet et al. (2003), Li et al. }(2005,2006)\end{array}$ \\
\hline \multirow{2}{*}{ Práticas de relacionamento com o cliente } & $\begin{array}{l}\text { Consultar clientes sobre decisão de novos } \\
\text { produtos. }\end{array}$ & Robb, Xie e Arthanari (2008) \\
\hline & $\begin{array}{l}\text { Consultar clientes sobre a programação da } \\
\text { produção. }\end{array}$ & Robb, Xie e Arthanari (2008), Pires (2004) \\
\hline \multirow{3}{*}{ Práticas de relacionamento com o fornecedor } & $\begin{array}{l}\text { Consultar os fornecedores sobre a decisão de } \\
\text { programação da produção. }\end{array}$ & Robb, Xie e Arthanari (2008) \\
\hline & $\begin{array}{l}\text { Consultar os fornecedores sobre novos } \\
\text { produtos. }\end{array}$ & Robb, Xie e Arthanari (2008) \\
\hline & $\begin{array}{c}\text { Apoiar os fornecedores na decisão de } \\
\text { aquisição de recursos. }\end{array}$ & $\begin{array}{l}\text { Tan, Lyman e Wisner (2002), Basnet et al. } \\
\text { (2003), Chow et al. (2008) }\end{array}$ \\
\hline Práticas de postergação & $\begin{array}{l}\text { Fazer a montagem final do produto o mais } \\
\text { próximo possivel do cliente final. }\end{array}$ & $\begin{array}{l}\text { Pires (2004), Chow et al. (2008), li et al. } \\
\qquad(2005,2006)\end{array}$ \\
\hline
\end{tabular}


(2006) constataram que a estratégia da empresa focal tem uma forte relação com a configuração da SC e o uso de práticas de SCM. Eles argumentam que a configuração da SC depende de variáveis como mercado, tipo de produto e características de parceria, como também adequação à estratégia. Então, a forma como a SC é desenvolvida e gerenciada é dependente do conteúdo da estratégia da empresa focal.

Considerando-se que, pela teoria top down do conteúdo da estratégia de produção, as PC tendem a afetar a área de decisão estrutural integração vertical, que elas, por sua vez, interferem em aspectos de SCM e que estratégia é uma variável que pode afetar a adoção de práticas de SCM, então formula-se a seguinte hipótese de pesquisa:

$\mathrm{H}_{1}$ : Pode haver uma associação entre prioridades competitivas de uma empresa e a adoção de práticas de SCM.

\section{Procedimentos metodológicos}

\subsection{Hipótese da pesquisa}

0 desenho de uma pesquisa quantitativa depende da definição de sua hipótese, a qual descreve o modelo teórico da pesquisa e suas variáveis de análise.

Em função da hipótese declarada é possível descrever o modelo teórico desta pesquisa (Figura 1). As PC formam um dos constructos da pesquisa e nesse constructo há várias variáveis que representam os atributos custo, qualidade, flexibilidade e entrega. As assertivas sistematizadas no Quadro 1 correspondem às variáveis de cada atributo utilizadas. 0 outro constructo são as práticas de SCM, no qual há muitas variáveis que representam os atributos (classificações) integração da SC, compartilhamento de informações, gestão de serviço ao cliente, relacionamento com o cliente, relacionamento com o fornecedor e postergação. Algumas das assertivas sistematizadas no Quadro 2 correspondem às variáveis utilizadas nesta pesquisa.

\subsection{Objeto de estudo}

As empresas estudadas nesta pesquisa atuam no setor eletroeletrônico brasileiro e são filiadas à Associação Brasileira da Indústria Elétrica e Eletrônica (ABINEE). Esse setor contempla operações nas áreas de automação industrial, comércio eletrônico, produção de componentes elétricos e eletrônicos, equipamentos industriais, equipamentos de geração, transmissão e distribuição de energia, equipamentos de informática e de telecomunicações. Atualmente, o setor responde por 4\% do PIB do Brasil (ASSOCIAÇÃO..., 2009).

Esse setor é dividido em geração de bens de consumo e de bens de infraestrutura e concorre internamente com produtos de países de economias emergentes. Uma de suas características é que ele é afetado por questões cambiais e por políticas públicas (investimentos em obras públicas). Isso ocorre porque após a abertura de mercado brasileiro, na década de 1990, intensificaram-se as importações de componentes eletrônicos (NASSIF, 2002).

Outra característica desse setor é que, segundo Kronmeyer Filho, Fachinello e Kliemann Neto (2004), em geral os produtos fabricados no Brasil são projetados no exterior e, como consequência, as atividades de engenharia de projetos dos componentes já foram previamente realizadas. Gavira (2008) constatou que, em geral, quando se tratam de empresas subsidiárias de multinacionais, a incumbência normalmente é adaptar produtos e serviços das multinacionais, customizar e nacionalizá-los para o mercado local. Um resultado similar foi encontrado por Tan e Hwang (2002) ao identificarem o status da área de pesquisa e desenvolvimento da indústria
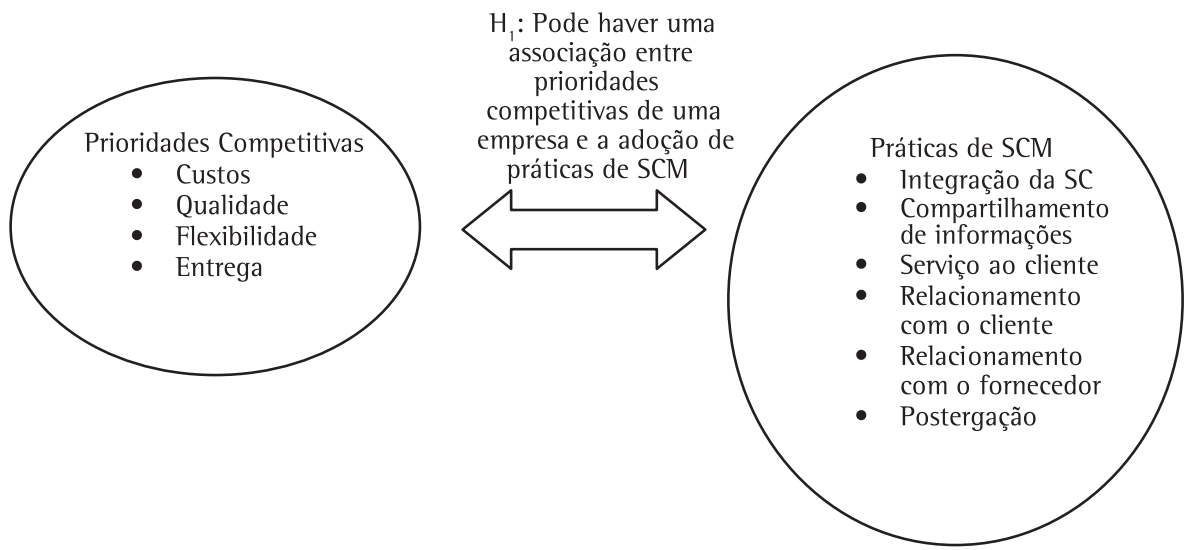

Figura 1. Modelo conceitual da pesquisa. 
eletrônica de empresas de Taiwan. Foi constatado que a pesquisa e o desenvolvimento nessa indústria são conduzidos por adaptações de projeto da tecnologia importada.

Hauser et al. (2007) descrevem como é a dinâmica dos segmentos de telecomunicações, informática e de componentes no Brasil. 0 processo produtivo básico restringe-se à montagem desses itens a partir de um conjunto total de componentes que são importados. 0 complexo eletroeletrônico brasileiro se destaca pela quase inexistência da produção de componentes eletrônicos. A inexistência de uma indústria que detenha o ciclo completo de produção de circuitos integrados (componentes que concentram, de forma crescente, as funcionalidades do produto final) impacta negativamente a competitividade do complexo eletroeletrônico nacional pelo custo, dificultando a inovação.

\subsection{Instrumento de coleta de dados}

0 instrumento de pesquisa utilizado foi um questionário fechado, dividido em três seções. A primeira caracteriza as empresas, a segunda mede a importância das PC e a terceira verifica o grau de implantação de práticas de SCM.

A seção de caracterização da empresa contemplava questões como porte; identificação da posição da empresa respondente em sua SC principal; poder de barganha na cadeia; e o perfil do respondente. Nesta seção, a escala adotada foi do tipo nominal. 0 Quadro 3 apresenta essas questões.

A segunda parte do questionário teve como base as assertivas sistematizadas no Quadro 1, pois elas são referentes às pesquisas que as validaram em estudos empíricos anteriores. São ao todo 13 afirmações a respeito das quatro PC. Cada afirmação foi avaliada quanto à relevância que a empresa atribui a ela. A partir do uso de uma escala ordinal do tipo likert de 5 pontos, sendo que 1 corresponde a extremamente irrelevante e 5 a extremamente relevante, foi possivel identificar a tendência das PC das empresas analisadas.

A parte três adota como referência as questões sistematizadas na literatura, descritas no Quadro 2 na coluna práticas associadas. São ao todo 22 assertivas que remetem às categorias (atributos) de práticas de SCM. Usou-se a escala ordinal do tipo Likert de 5 pontos, onde 1 é não implantado e 5 é completamente implantado, para avaliar o grau de implantação de cada prática de SCM pelas empresas.

\subsection{Pré-teste e procedimentos de coleta de dados}

Esta pesquisa adotou como procedimento de coleta de dados o questionário autoadministrável. Uma recomendação importante que este trabalho seguiu foi aplicar um pré-teste do questionário autoadministrado antes de seu envio para as unidades de análise. Synodinos (2003) afirma que o teste do questionário é essencial, pois é possível identificar questões a serem reformuladas e que geram mal entendidos.

0 pré-teste desta pesquisa foi realizado em duas etapas. A primeira com 5 professores da área de gestão de operações e 3 alunos de pós-graduação em engenharia de produção, nível doutorado, que estudam o tema estratégia; e a segunda com 8 gerentes de áreas funcionais como logística e planejamento e controle da produção (PCP) de empresas fornecedoras de componentes (que fazem parte do setor eletroeletrônico) para o setor automotivo/linha branca. Foram enviados e-mails individuais para cada participante explicando os objetivos da pesquisa e pedindo a colaboração na avaliação do instrumento da pesquisa. Anexados aos e-mails estavam: carta de apresentação do trabalho; recomendações de preenchimento; agradecimento por participar da pesquisa; e o questionário.

Quadro 3. Questões da primeira seção do questionário.

\begin{tabular}{|c|c|c|}
\hline Questão & Opções & Referências/Estudos que utilizaram \\
\hline Porte da empresa & $\begin{array}{l}\text { Micro empresa - } 1 \text { a } 19 \text { funcionários, } \\
\text { Pequena empresa - } 20 \text { a } 99 \text { funcionários, } \\
\text { Média empresa - } 100 \text { a } 499 \text { funcionários, } \\
\text { Grande empresa - } 500 \text { ou mais funcionários. }\end{array}$ & $\begin{array}{l}\text { Sebrae (2009), Robb, Xie e Arthanari } \\
\text { (2008), Demeter, Gelei e Jenei } \\
\text { (2006), Li et al. (2005, 2006), } \\
\text { Olhager e Selldin (2004), Tan, } \\
\text { Lyman e Wisner (2002), Tan (2002) }\end{array}$ \\
\hline $\begin{array}{c}\text { Posição da empresa na cadeia de } \\
\text { suprimentos principal }\end{array}$ & $\begin{array}{l}\text { Montadora, } \\
\text { Fornecedor de matéria-prima, } \\
\text { Fornecedor de componentes, } \\
\text { Distribuidor, } \\
\text { Varejo. }\end{array}$ & $\begin{array}{c}\text { Spens e Wisner (2009), Olhager e } \\
\text { Selldin (2004), Basnet et al. (2003), } \\
\text { Tan (2002) }\end{array}$ \\
\hline Poder de barganha & $\begin{array}{l}\text { Sua empresa, } \\
\text { Seus fornecedores, } \\
\text { Seus clientes. }\end{array}$ & \\
\hline
\end{tabular}


0 pré-teste durou 65 dias, tendo como principais resultados: a) o cálculo do alfa de Cronbach dos constructos da pesquisa (alfa $=0,7216$ para 0 constructo de PC; e alfa $=0,9725$ para o constructo de práticas de $\mathrm{SCM}$ ); e b) a reformulação ou exclusão de algumas questões referentes ao constructo práticas de SCM, para deixá-las mais claras.

Após o indicativo de que o questionário estava adequado para medir as variáveis desta pesquisa, iniciou-se o procedimento de coleta de dados. Foram necessários quatro passos durante a etapa de coleta. 0 primeiro foi entrar em contato com a área de relações públicas da ABINEE para obter a base de dados atualizada de seus filiados. Tendo o nome e o e-mail do potencial respondente de cada empresa, iniciou-se o segundo passo. Esse consistiu em formatar o questionário de uma forma que fosse fácil de acessar e de responder. Utilizaram-se serviços de internet para formular uma página eletrônica com o conteúdo do questionário. A terceira etapa foi enviar e-mails personalizados, a partir do mecanismo de mala direta, para todos os contatos da planilha da ABINEE. Foram enviados e-mails para as 552 empresas cadastradas na planilha obtida. No entanto, 20 retornaram por razões diversas, como: o e-mail estava errado, a pessoa de contato não trabalhava mais na empresa etc. A quarta etapa foi gerenciar o retorno dos questionários e fazer eventuais intervenções. A primeira onda de e-mails durou 10 dias, a segunda, 18 dias e a última, 16 dias.

Depois de transcorridos 44 dias de pesquisa e três ondas de e-mails, a taxa de retorno obtida correspondeu a 20\% (107 respondentes), considerada adequada, conforme Malhotra e Grover (1998).

\subsection{Técnicas de análise dos dados}

Inicialmente realizaram-se análises estatísticas descritivas, com o propósito entender a distribuição de frequência de cada variável conforme sua tendência central e de dispersão. Assim, podem-se condensar os dados e entender quais são as principais práticas de SCM adotadas pelas empresas do setor eletroeletrônico.

A segunda técnica empregada foi a análise de componentes principais, que foi aplicada para todas as variáveis de um mesmo constructo. A análise de componentes principais foi aplicada para estudar as interrelações entre variáveis do mesmo constructo, com vistas ao agrupamento de variáveis afins em fatores, ou seja, verificando como as diversas variáveis analisadas se comportam no âmbito de cada constructo (prioridades competitivas [COM_P] e práticas de SCM [SCM_P]). Assim, a análise de componentes principais divide as variáveis em grupos (fatores), resumindo o seu padrão de relacionamento. $A$ análise de componentes principais resultou em um modelo com quatro fatores para práticas de SCM e três fatores para práticas de PC.

Em seguida, cada um desses fatores foi analisado quanto à qualidade de suas medidas, para verificar se eram estatisticamente válidas. Essas medidas de qualidade foram obtidas por meio dos softwares SPSS e SmartPLS. O SPSS foi útil para verificar medidas como adequação da amostra. Por meio do SmartPLS, utilizando a técnica estatística Partial Least Squares (PLS), foram obtidas e avaliadas a confiabilidade a validade de cada variável, antes de se proceder à interpretação do modelo estrutural. Com base nessas análises, verificou-se se a $\mathrm{H}_{1}$ deveria ser aceita ou não.

Resgatando-se as questões de pesquisa anunciadas na seção 1 deste artigo, o Quadro 4 apresenta cada questão de pesquisa, a forma de análise dos dados e os resultados esperados.

A lista de variáveis da pesquisa e de seus respectivos códigos encontram-se no Apêndice 1.

\section{Resultados da pesquisa}

\subsection{Perfil das empresas respondentes}

Ao todo, 107 empresas aceitaram participar da pesquisa e o perfil dos respondentes teve o predomínio dos cargos de diretores e gerentes de diversas áreas como marketing, suprimentos, operações e vendas. Esse resultado era de certa forma esperado, pois, segundo Tan, Lyman e Wisner (2002), Li et al. (2005) e Hsu et al. (2009), o cargo de gerente é o mais adequado para pesquisas na área de práticas de SCM.

Quadro 4. Relação entre questões de pesquisa, formas de análise dos dados obtidos e resultados esperados.

\begin{tabular}{|c|c|c|}
\hline Questão de pesquisa & Técnica de análise de dados & Resultados esperados \\
\hline $\begin{array}{l}\text { Quais são as práticas de SCM que estão sendo } \\
\text { adotadas no setor eletroeletrônico brasileiro? }\end{array}$ & Técnicas de estatística descritiva & $\begin{array}{l}\text { ldentificar, a partir das maiores médias/ } \\
\text { percentual/quartil superior, as práticas de } \\
\text { SCM mais adotadas no setor. }\end{array}$ \\
\hline $\begin{array}{l}\text { As prioridades competitivas da produção das } \\
\text { empresas desse setor se relacionam com a } \\
\text { adoção de práticas de SCM? }\end{array}$ & $\begin{array}{c}\text { Técnicas de estatística multivariada - análise } \\
\text { de componentes principais e PLS (modelagem } \\
\text { de equações estruturais) }\end{array}$ & $\begin{array}{c}\text { Verificar se há relações significativas entre as } \\
\text { PC das empresas do setor eletroeletrônico e } \\
\text { suas práticas de SCM. }\end{array}$ \\
\hline
\end{tabular}


A estratificação das empresas respondentes por posição na SC, porte e identificação do poder de barganha, está expressa na Tabela 1. A posição das empresas em suas SC principais é predominantemente montadora (76,6\%); em relação ao porte, as pequenas $(31,8 \%)$ e médias empresas $(42,1 \%)$ são as que se destacam em percentual de participação na pesquisa; e em relação ao elo que possui maior poder de barganha na cadeia das empresas pesquisadas, os clientes $(81,3 \%)$ se destacam como os que conduzem a SC.

\subsection{Adoção de práticas de SCM}

Quanto à adoção das práticas de SCM, tem-se que os valores percentuais variaram entre $41 \%$ a $75 \%$ (Tabela 2). Usa-se como parâmetro para destacar as variáveis mais implantadas aquelas com 25\% de valores percentuais maiores (quartil superior). Há 6 práticas que podem ser destacadas (faixa entre $63 \%$ a $75 \%):$

- Obtenção de feedback dos clientes finais sobre a adequação do produto (V17SCM);

- Determinação das necessidades futuras do cliente (V15SCM);

- Integração das atividades de desenvolvimento de produto com os fornecedores (V2SCM);

- Colaboração dos fornecedores na previsão de demanda (V5SCM);

- Consulta aos clientes para apoiar a decisão de novos produtos (V18SCM); e

- Integração das atividades de desenvolvimento de produtos com os clientes (V1SCM).

As práticas com menor percentual de implantação (25\% das variáveis com menor valor percentual) são: comunicação das estratégias futuras aos fornecedores (V16SCM); compartilhamento de informações com os fornecedores sobre lançamentos de produtos (V13SCM); participação no marketing dos clientes (V14SCM); montagem próxima ao cliente (V22SCM); compartilhamento formal de informações de custos com os clientes (V12SCM); e formação de equipes multifuncionais (V11SCM).

\subsection{Relação entre PC e práticas de SCM}

Inicialmente, usando o software SPSS, a qualidade do modelo proposto pela análise de componentes principais foi analisada pela verificação de: a) adequação da amostra pelo teste KMO (Kaiser-Meyer-Olkin); b) cálculo do alfa de Cronbach para cada fator; c) o Eigenvalue para cada fator, onde foram extraídos os fatores com valores iguais ou superiores a 1; e d) a variância acumulada explicada.

A redução dos dados de todas as variáveis, tanto do construto prioridades competitivas (COM_P), quanto para o construto práticas de Supply Chain Management (SCM_P) foi realizada usando a análise de componentes principais, pelo método Varimax. Esse procedimento foi realizado independentemente para COM_P e SCM_P.

Em relação ao constructo prioridades competitivas (COM_P), três fatores foram formados, explicando uma variância acumulada aproximada de 50\%. 0 teste KMO, que verifica a adequação da amostra, foi de 0,682, considerado adequado. A fim de refinar os resultados, a análise de componentes principais passou a revelar apenas cargas de variáveis acima de 0,6, fatores com Eingenvalues maior que 1 e coeficientes da diagonal da matriz anti-imagem maior do que 0,6 . Foram verificados também se a comunalidade é igual ou superior a 0,5 para cada variável (HAIR JUNIOR et al., 2005). COM_P passou a ser formado por três fatores: 1) COM_P_1 (variáveis V11CP, V3CP e V5CP); 2) COM_P_2 (variáveis V10CP e V13CP); e 3) COM_P_3 (variáveis V7CP e V9CP). 0 fator COM_P_1 combina variáveis da PC flexibilidade relativas a produto, portanto, seu rótulo recebeu o nome flexibilidade de produto. Em função do perfil das variáveis, o rótulo do fator COM_P_2 combina variáveis da $P C$ qualidade e é chamado padrão de qualidade. 0 fator COM_P_3 combina a variável PC custos e a variável da PC flexibilidade. Como volume de produção (V9CP) está relacionado a custo de produção (V7CP) (quanto maior o volume, menor o custo de produção), o rótulo dessa variável é volume de produção.

Já em relação ao constructo práticas de SCM (SCM_P), quatro fatores foram formados, explicando uma variância acumulada de aproximadamente 65\%.

Tabela 1. Caracterização da amostra da pesquisa.

\begin{tabular}{ccccc}
\hline & $\begin{array}{c}\text { Fornecedor de } \\
\text { matéria-prima (\%) }\end{array}$ & $\begin{array}{c}\text { Fornecedor de } \\
\text { componentes (\%) }\end{array}$ & Montadora (\%) & Distribuidor (\%) \\
\hline Posição & 0,9 & 15,9 & 76,6 & 4,7 \\
Micro empresa (\%) & Pequena empresa (\%) & Média Empresa (\%) & Grande empresa (\%) \\
\hline Porte & 10,3 & 31,8 & 42 & 15,9 \\
\hline Poder de barganha & Seus fornecedores (\%) & Sua empresa (\%) & Seus clientes (\%) & \\
\hline
\end{tabular}


0 teste KMO foi 0,879, considerado adequado. A análise de componentes principais revelou valores acima de 0,6 e fatores com Eingenvalues maiores que 1 e coeficientes da diagonal da matriz anti-imagem acima de 0,6. Verificou-se também se a comunalidade é igual ou superior a 0,5 para cada variável (HAIR JUNIOR et al., 2005). Como consequência,
SCM_P passou a ser formado por quatro fatores: 1) SCM_P_1 (variáveis V10SCM, V5SCM, V6SCM, V7SCM, V8SCM e V9SCM); 2) SCM_P_2 (variáveis V17SCM, V18SCM, V19SCM, V20SCM e V21SCM); 3) SCM_P_3 (variáveis V14SCM, V15SCM, V3SCM e V4SCM); e 4) SCM_P_4 (variáveis V12SCM e V22SCM). 0 fator SCM_P_1 é denominado integração da SC

Tabela 2. Práticas de SCM implantadas pelas empresas pesquisadas.

\begin{tabular}{|c|c|c|c|c|c|c|c|}
\hline Variável & Média & Desvio padrão & $\begin{array}{l}\text { Coeficiente de } \\
\text { variância }\end{array}$ & Mediana & Máximo & Mínimo & Percentual (\%) \\
\hline Feedback cliente (V17SCM) & 3,77 & 1,112 & 0,294 & 4 & 5,00 & 1,00 & 75 \\
\hline $\begin{array}{l}\text { Necessidade futura cliente } \\
\text { (V15SCM) }\end{array}$ & 3,30 & 1,191 & 0,361 & 4 & 5,00 & 1,00 & 66 \\
\hline $\begin{array}{l}\text { Integração fornecedor } \\
\text { (V2SCM) }\end{array}$ & 3,32 & 1,364 & 0,411 & 4 & 5,00 & 1,00 & 66 \\
\hline $\begin{array}{l}\text { Colaboração fornecedor } \\
\text { previsão demanda (V5SCM) }\end{array}$ & 3,24 & 1,338 & 0,413 & 4 & 5,00 & 1,00 & 65 \\
\hline $\begin{array}{l}\text { Apoio decisão cliente novo } \\
\text { produto (V18SCM) }\end{array}$ & 3,27 & 1,263 & 0,386 & 4 & 5,00 & 1,00 & 65 \\
\hline Integração cliente (V1SCM) & 3,15 & 1,309 & 0,415 & 3 & 5,00 & 1,00 & 63 \\
\hline $\begin{array}{c}\text { Colaboração fornecedor } \\
\text { planejamento produção } \\
\text { (V9SCM) }\end{array}$ & 3,09 & 1,438 & 0,465 & 3 & 5,00 & 1,00 & 62 \\
\hline $\begin{array}{c}\text { Colaboração cliente } \\
\text { previsão demanda (V6SCM) }\end{array}$ & 3,09 & 1,285 & 0,416 & 3 & 5,00 & 1,00 & 62 \\
\hline $\begin{array}{c}\text { Colaboração fornecedor } \\
\text { planejamento estoque } \\
\text { (V7SCM) }\end{array}$ & 3,07 & 1,445 & 0,470 & 3 & 5,00 & 1,00 & 61 \\
\hline $\begin{array}{c}\text { Colaboração cliente } \\
\text { planejamento estoque } \\
\text { (V8SCM) }\end{array}$ & 3,03 & 1,397 & 0,461 & 3 & 5,00 & 1,00 & 61 \\
\hline $\begin{array}{c}\text { Apoio fornecedor } \\
\text { desenvolvimento produto } \\
\text { (V21SCM) }\end{array}$ & 3,07 & 1,406 & 0,457 & 4 & 5,00 & 1,00 & 61 \\
\hline $\begin{array}{l}\text { Colaboração cliente } \\
\text { planejamento produção } \\
\text { (V10SCM) }\end{array}$ & 2,97 & 1,404 & 0,473 & 3 & 5,00 & 1,00 & 59 \\
\hline $\begin{array}{l}\text { Consulta fornecedor } \\
\text { programação produção } \\
\text { (V20SCM) }\end{array}$ & 2,92 & 1,487 & 0,510 & 3 & 5,00 & 1,00 & 58 \\
\hline $\begin{array}{c}\text { Consulta cliente } \\
\text { programação produção } \\
\text { (V19SCM) }\end{array}$ & 2,87 & 1,530 & 0,533 & 3 & 5,00 & 1,00 & 57 \\
\hline $\begin{array}{l}\text { Envolvimento fornecedor } \\
\text { planos (V4SCM) }\end{array}$ & 2,79 & 1,419 & 0,508 & 3 & 5,00 & 1,00 & 56 \\
\hline $\begin{array}{l}\text { Envolvimento cliente } \\
\text { planos (V3SCM) }\end{array}$ & 2,79 & 1,358 & 0,486 & 3 & 5,00 & 1,00 & 56 \\
\hline $\begin{array}{l}\text { Comunicação fornecedor } \\
\text { estratégia futura (V16SCM) }\end{array}$ & 2,64 & 1,369 & 0,518 & 3 & 5,00 & 1,00 & 53 \\
\hline $\begin{array}{l}\text { Compartilhamento } \\
\text { informação lançamento } \\
\text { produto fornecedor } \\
\text { (V13SCM) }\end{array}$ & 2,61 & 1,323 & 0,506 & 3 & 5,00 & 1,00 & 52 \\
\hline $\begin{array}{l}\text { Participação marketing } \\
\text { cliente (V14SCM) }\end{array}$ & 2,53 & 1,383 & 0,546 & 3 & 5,00 & 1,00 & 51 \\
\hline $\begin{array}{l}\text { Montagem próxima cliente } \\
\text { (V22SCM) }\end{array}$ & 2,38 & 1,527 & 0,641 & 2 & 5,00 & 1,00 & 48 \\
\hline $\begin{array}{c}\text { Compartilhamento } \\
\text { informação custo cliente } \\
\text { (V12SCM) }\end{array}$ & 2,12 & 1,385 & 0,653 & 1 & 5,00 & 1,00 & 42 \\
\hline $\begin{array}{c}\text { Criação de equipes } \\
\text { multifuncionais (V11SCM) }\end{array}$ & 2,05 & 1,334 & 0,650 & 1 & 5,00 & 1,00 & 41 \\
\hline Média & & & & 3,05 & & & \\
\hline
\end{tabular}


para apoiar atividades de planejamento e controle da produção (PCP), uma vez que agrupa variáveis relativas a planejamento de estoque, produção e previsão de demanda entre clientes e fornecedores. 0 fator SCM_P_2 é rotulado compartilhamento de informações para direcionar decisões de produto e produção, pois é composto de variáveis que tratam de apoio e consulta a cliente e fornecedor sobre programação da produção e desenvolvimento de novos produtos. 0 fator SCM_P_3 é intitulado gestão de suporte aos planos futuros dos clientes, uma vez que agrupa variáveis que tratam de gestão de envolvimento com os clientes. Já o fator SCM_P_4 é denominado relacionamento estreito com o cliente por se tratar da união de variáveis não triviais, como compartilhamento aberto sobre custos de produção com o cliente.

A Tabela 3 mostra as variáveis que integram o modelo estrutural após a purificação do modelo com base na análise de componentes principais e nos indicadores de qualidade adotados.

Já a Tabela 4 mostra as variáveis que não foram aprovadas nos indicadores de qualidade da análise de componentes principais, apresentando justificativas para sua exclusão.

Em seguida, Structural Equation Modeling using Partial Least Squares (SEM-PLS) foi utilizada. A modelagem de equações estruturais por meio de PLS é considerada uma análise multivariada de segunda geração e é especialmente útil quando se trabalha com a teoria complexa e em estágios iniciais de desenvolvimento. Um modelo foi criado contendo os constructos obtidos a partir da análise de componentes principais, como explicado acima. 0 objetivo desse procedimento foi testar a validade e confiabilidade do modelo de análise dos componentes principais. As análises foram realizadas usando o software SmartPLS 2.03 (SOSIK; KAHAI; PIOVOSO, 2009).

De forma geral, o modelo estrutural proposto é adequado, uma vez que o Goodness of Fit (GoF), que avalia a qualidade geral do modelo, foi de aproximadamente 0,6, valor considerado adequado.

Além desse indicador global de qualidade (GoF), indicadores de boa qualidade para o modelo proposto (Figura 2) foram alcançados em termos de variância média extraída (validade convergente), confiabilidade composta, alfa de Cronbach e comunalidades, tanto para o construto COM_P quanto para o SCM_P. Para checar a confiabilidade (que apura a precisão com que o constructo mede aquilo que realmente deveria medir) e validade satisfatórias (que testa a relação de uma variável com outra variável de um mesmo constructo), o valor de confiabilidade composta deve ser superior a 0,7 , enquanto o valor da validade convergente deve ser superior a 0,5. Confiabilidade de construto foi avaliada utilizando confiabilidade composta. Já validade convergente foi analisada pela variância média extraída. A Tabela 5 mostra que todos os valores de confiabilidade composta são superiores a 0,7 e todos os valores de variância média extraída são superiores a 0,5 (FOLTZ, 2008). Os coeficientes de alfa de Cronbach e as comunalidades também são considerados adequados.

Outra medida importante para avaliar o modelo estrutural é a partir da validade discriminante. Esta é realizada por meio da observação das correlações entre constructos, que devem ser menores que a raiz quadrada da AVE (COSTA; SOUZA; SILVA, 2008). A Tabela 6 traz as correlações entre os fatores dos constructos principais da pesquisa. A diagonal em negrito representa a raiz quadrada da variância média extraída, obtendo-se resultados consistentes.

Com vistas ao teste de robustez do modelo, um bootstrap de 1.000 subamostras foi utilizado para estimar a significância estatística das relações entre as variáveis propostas e os constructos (Figura 3). Todas as relações do modelo são estatisticamente válidas ao nível de significância ( $p$ value) menor ou igual a 0,05, exceto a relação entre aos constructos COM_P e SCM_P, o que indica que essa relação não é estatisticamente válida.

Tabela 3. Variáveis que compõem o modelo estrutural após a purificação.

\begin{tabular}{|c|c|c|c|}
\hline Constructos latentes & Fatores & Rótulo & Variáveis \\
\hline \multirow{4}{*}{ SCM_P } & SCM_P_1 & $\begin{array}{c}\text { Integração da SC para apoiar } \\
\text { atividade de PCP }\end{array}$ & $\begin{array}{l}\text { V10SCM V5SCM } \\
\text { V6SCM V7SCM } \\
\text { V8SCM V9SCM }\end{array}$ \\
\hline & SCM_P_2 & $\begin{array}{c}\text { Compartilhamento de informações } \\
\text { para direcionar decisões de produto } \\
\text { e produção }\end{array}$ & $\begin{array}{l}\text { V17SCM V18SCM } \\
\text { V19SCM V20SCM } \\
\text { V21SCM }\end{array}$ \\
\hline & SCM_P_3 & $\begin{array}{l}\text { Gestão de suporte aos planos } \\
\text { futuros dos clientes }\end{array}$ & $\begin{array}{l}\text { V14SCM V15SCM } \\
\text { V3SCM V4SCM }\end{array}$ \\
\hline & SCM_P_4 & $\begin{array}{c}\text { Relacionamento estreito com o } \\
\text { cliente }\end{array}$ & V12SCM V22SCM \\
\hline \multirow{3}{*}{ COMP_P } & COMP_P_1 & Flexibilidade de produto & V11CP V3CP V5CP \\
\hline & COM_P_2 & Padrão de qualidade & V10CP V13CP \\
\hline & COM_P_3 & Volume de produção & V7CP V9CP \\
\hline
\end{tabular}




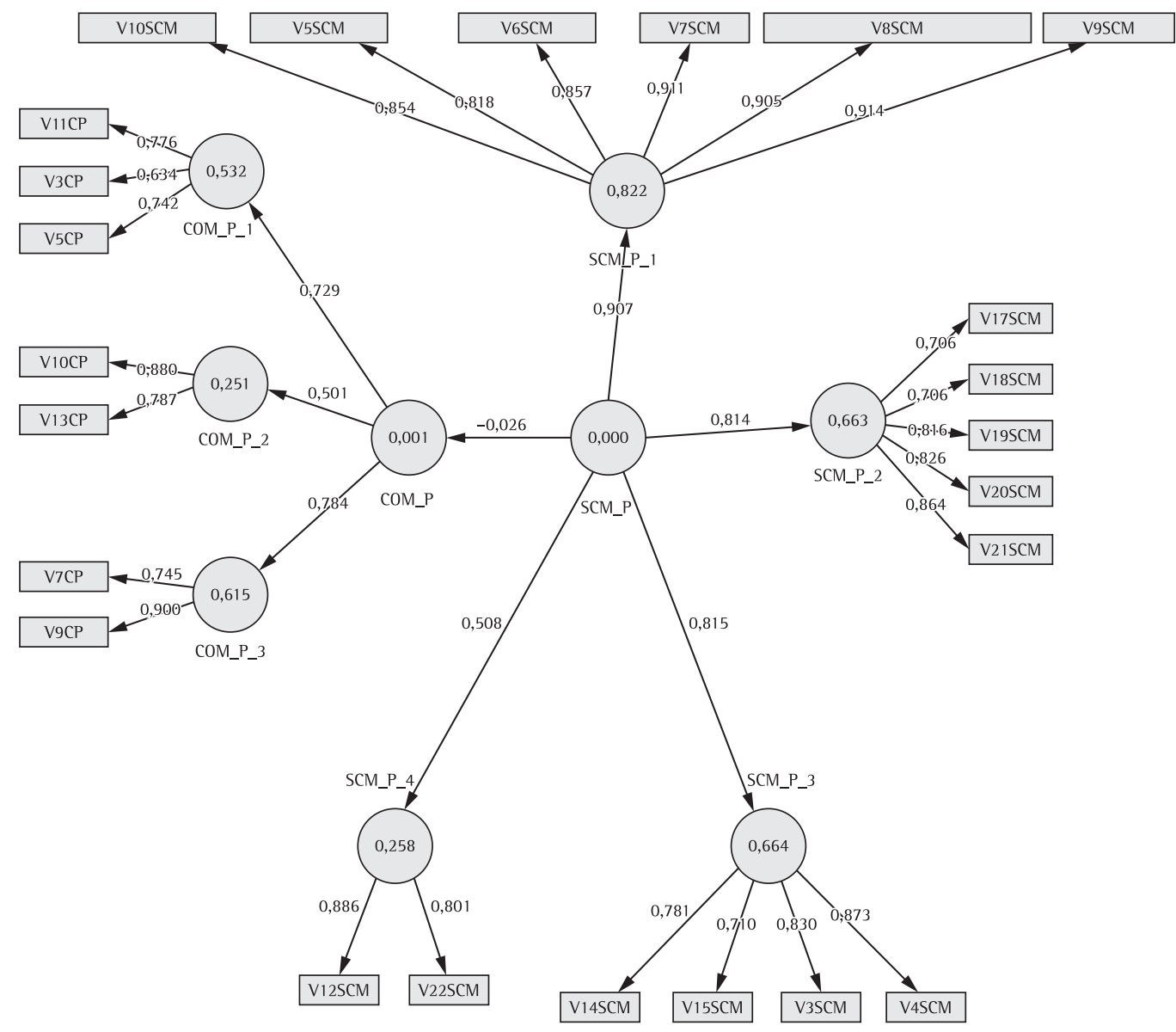

Figura 2. Modelo estrutural purificado e mensurado.

Tabela 4. Variáveis excluídas após a purificação do modelo estrutural e suas justificativas.

\begin{tabular}{ccc} 
Constructo latente & $\begin{array}{c}\text { Variáveis } \\
\text { excluídas após } \\
\text { a principal dos } \\
\text { componentes } \\
\text { principais }\end{array}$ & $\begin{array}{c}\text { Critério } \\
(\mathrm{a}=\text { diagonal da matriz } \\
\text { anti-imagem }<0,6 ; \\
\mathrm{B}=\text { comunalidade }<0,5)\end{array}$ \\
\hline COMP_P & V1CP & $\mathrm{b}$ \\
& V2CP & $\mathrm{a}$ \\
& V4CP & $\mathrm{b}$ \\
V6CP & $\mathrm{b}$ \\
\hline
\end{tabular}

Tabela 5. Valores de confiabilidade e de validade do modelo estrutural.

\begin{tabular}{lcccc}
\hline & AVE & $\begin{array}{c}\text { Confiabilidade } \\
\text { composta }\end{array}$ & $\begin{array}{c}\text { Alfa } \\
\text { Cronbach }\end{array}$ & Comunalidade \\
\hline COM_P_1 & 0,518 & 0,762 & 0,537 & 0,518 \\
COM_P_2 & 0,697 & 0,821 & 0,571 & 0,697 \\
COM_P_3 & 0,683 & 0,810 & 0,551 & 0,683 \\
SCM_P_1 & 0,769 & 0,952 & 0,940 & 0,769 \\
SCM_P_2 & 0,585 & 0,875 & 0,822 & 0,585 \\
SCM_P_3 & 0,641 & 0,877 & 0,812 & 0,641 \\
SCM_P_4 & 0,714 & 0,833 & 0,604 & 0,714 \\
\hline
\end{tabular}

\section{Discussão}

A identificação das práticas de SCM que estão sendo adotadas na amostra do setor eletroeletrônico brasileiro sob análise indica que há uma tendência de adoção de práticas direcionadas para os clientes. A média das medianas da implantação das práticas de SCM indica que o estágio atual tende a parcialmente implantada, uma vez que a média foi de 3,05. As práticas assinaladas como de mais representatividade em relação ao percentual de adoção do lado do cliente são:

- Obtenção de feedback dos clientes finais sobre a adequação do produto (V17SCM);

- Determinação das necessidades futuras do cliente (V15SCM);

- Consulta aos clientes para apoiar a decisão de novos produtos (V18SCM); e

- Integração das atividades de desenvolvimento de produtos com os clientes (V1SCM).

Essas práticas estão relacionadas às categorias de integração da SC, gestão do relacionamento com o 
cliente, gestão de serviço ao cliente e compartilhamento de informações. Ou seja, todas as categorias relativas às práticas de SCM voltadas para clientes foram representadas por pelo menos uma prática (variável) correspondente.

Do lado do fornecedor, as práticas destacáveis são:

- Integração das atividades de desenvolvimento de produto com os fornecedores (V2SCM); e

- Colaboração dos fornecedores na previsão de demanda (V5SCM).

A categoria relativa a essas práticas é integração da SC.
Houve mais práticas de SCM que são implantadas com os clientes e que merecem destaque (25\% das variáveis com maior valor percentual), além das categorias serem mais diversificadas a jusante (4 categorias) do que a montante (apenas uma categoria). lsso pode ser uma evidência da influência do elo forte da cadeia, ou seja, os clientes exercem poder sobre as empresas a montante, o que eventualmente implica em maiores esforços de relacionamento e suporte aos clientes (MOURITSEN; SKJOTT-LARSEN; KOTZAB, 2003).

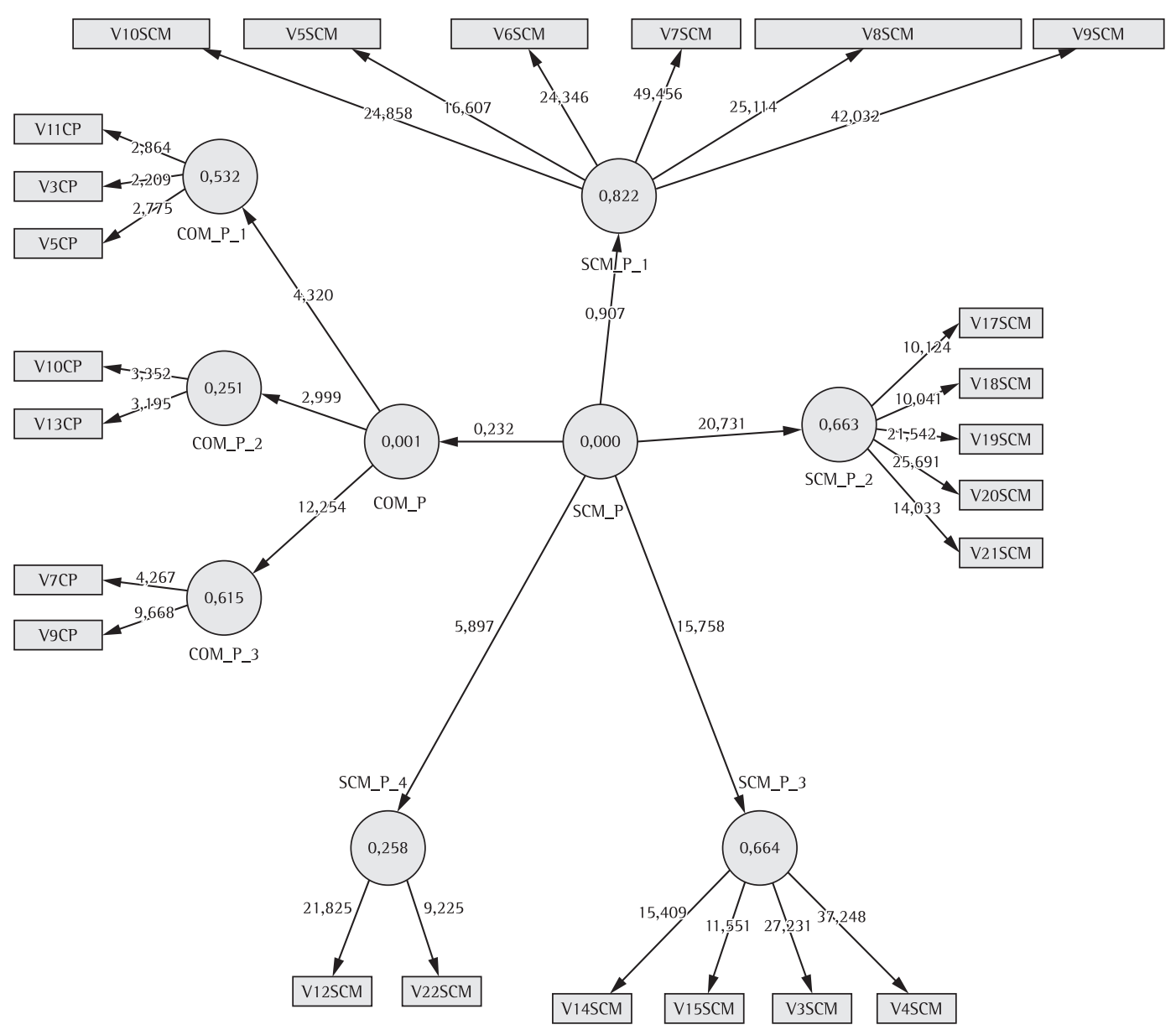

Figura 3. Modelo estrutural purificado depois do processamento do bootstrapping.

Tabela 6. Matriz de correlação dos constructos.

\begin{tabular}{lccccccc}
\hline & COM_P_1 & COM_P_2 & COM_P_3 & SCM_P_1 & SCM_P_2 & SCM_P_3 & SCM_P_4 \\
\hline COM_P_1 & 0,720 & & & & & & \\
COM_P_2 & 0,501 & 0,835 & & & & & \\
COM_P_3 & 0,784 & 0,303 & 0,826 & & & & \\
SCM_P_1 & $-0,015$ & $-0,053$ & 0,003 & 0,877 & & & \\
SCM_P_2 & $-0,012$ & $-0,090$ & 0,060 & 0,814 & 0,765 & & 0,801 \\
SCM_P_3 & $-0,001$ & 0,013 & $-0,049$ & 0,815 & 0,629 & 0,801 & 0,394 \\
SCM_P_4 & $-0,126$ & $-0,038$ & $-0,121$ & 0,508 & 0,342 & & \\
\hline
\end{tabular}


Tabela 7. Resultados da análise estatística da hipótese da pesquisa.

\begin{tabular}{ccc}
\hline Hipótese & Conclusão & Justificativa \\
\hline $\mathrm{H}_{1}-$ Há relacionamento & & Relação não \\
significativo entre prioridades & Não & significativa \\
competitivas (COM_P) e práticas de & suportada & $(p$ value maior \\
SCM (SCM_P) & que 0,05) \\
\hline
\end{tabular}

A hipótese $\mathrm{H}_{1}$ foi elaborada com base nos argumentos de Rudberg e Olhager (2003), Maia, Cerra e Alves Filho (2005), Demeter, Gelei e Jenei (2006), Vachon, Halley e Beaulieu (2009) e Salles et al. (2010), os quais indicam que, em geral, as PC impactam na forma de gerenciar e estruturar a SC. No entanto, essa hipótese, nesta pesquisa, não foi suportada estatisticamente (Tabela 7). Provavelmente, a justificativa seja o fato de as empresas respondentes não serem as empresas focais em suas SC principais. Demeter, Gelei e Jenei (2006) fizeram essa ressalva ao sugerir que a estratégia da empresa focal tem forte relação com a configuração da SC e com o uso de práticas de SCM.

\section{Conclusões}

Os objetivos principais desta pesquisa eram identificar quais práticas de SCM estão sendo adotadas nas empresas do setor eletroeletrônico brasileiro e verificar se as prioridades competitivas da produção das empresas se relacionam com a adoção de suas práticas de SCM. Este trabalho conseguiu alcançar os objetivos postos a partir de uma e-mail surveye uso de técnicas estatísticas descritivas e multivariadas.

Como resultados centrais, podem-se destacar:

- As práticas de SCM que estão sendo mais implantadas são: obtenção de feedback dos clientes finais sobre a adequação do produto, determinação das necessidades futuras do cliente, integração das atividades de desenvolvimento de produto com os fornecedores, colaboração dos fornecedores na previsão de demanda, consulta aos clientes para apoiar a decisão de novos produtos e integração das atividades de desenvolvimento de produtos com os clientes;

- Não foram verificadas relações significativas entre as PC das empresas do setor eletroeletrônico e a adoção de práticas de SCM.

Este trabalho traz um estudo empírico da realidade de empresas do setor eletroeletrônico brasileiro, contribuindo com evidências sobre o tema práticas de SCM, como:

- As empresas da amostra do setor eletroeletrônico tendem a estar no estágio parcialmente implantado para diversas práticas de SCM, exceto para as práticas consideradas estratégicas, pois provavelmente os clientes não estão abertos à integração e/ou há falta confiança entre os pares;

- Há mais práticas adotadas com os clientes do que com os fornecedores e as práticas voltadas aos clientes englobam todas as categorias de práticas, enquanto que, do lado do fornecedor, há apenas uma categoria; e

- Provavelmente, a posição do elo forte na cadeia afeta a adoção de práticas.

Nesta pesquisa não foi constatado que existem relações entre as PC das empresas estudadas e as práticas de SCM implantadas. Uma explicação para tal resultado é o fato de as cadeias eletroeletrônicas serem dirigidas pelos clientes e não pelas montadoras. Portanto, não foram detectadas as relações previamente esperadas conforme indicativos da literatura, o que pode ser verificado quando se avalia o baixo percentual de participação de empresas varejistas na pesquisa survey, elo esse que tende a ser o focal (tende a ter maior poder de barganha) nas cadeias do setor eletroeletrônico.

Os resultados desta pesquisa são úteis para fundamentar decisões gerenciais, uma vez que destacam as características do setor eletroeletrônico brasileiro, inserido numa cadeia de fornecimento global, e identificam o perfil das práticas de SCM desse setor, que são voltadas à integração e apoio às atividades de desenvolvimento de produtos com os clientes.

Como limitação desta pesquisa, pode-se citar a modesta taxa de retorno, mas que se mostrou adequada aos propósitos das análises estatísticas realizadas.

Seria interessante, para estudos futuros, fazer uma survey com os mesmos propósitos desta mais incluindo empresas focais em suas SC principais, pois assim poder-se-ia certificar que esta condição está relacionada à influência das PC na adoção de práticas de SCM. Outra sugestão seria verificar outros fatores que potencialmente podem afetar a adoção de práticas de SCM, como porte das empresas, posição na SC e setor produtivo.

\section{Referências}

ARSHINDER, A. K.; DESHMUKN, S. G. Supply chain coordination: perspectives, empirical studies and research direction. International Journal of Production Economics, v. 15, p. 316-335, 2008. http://dx.doi. org/10.1016/j.ijpe.2008.05.011

ASSOCIAÇÃO BRASILEIRA DA INDÚSTRIA NACIONAL DE ELÉTRICA ELETRÔNICA - ABINEE. Disponível em: $<$ www.abinee.org.br>. Acesso em: maio 2009.

BASNET, C. et al. Benchmarking supply chain management practice in New Zealand. Supply Chain Management: An 
International Journal, v. 8, n. 1, p. 57-64, 2003. http:// dx.doi.org/10.1108/13598540310463369

CHOW, W. S. et al. Supply chain management in the US and Taiwan: an empirical study. Omega, v. 36, p. 665-679, 2008. http://dx.doi.org/10.1016/j. omega.2006.01.001

COSTA, A. C. F.; SOUZA, S. S.; SILVA, L. C. T. Investigação sobre a satisfação do usuário dos serviços prestados pelo metrô de São Paulo: um estudo exploratório, descritivo e ilustrativo com a utilização do modelo de equações estruturais. Revista de Gestão da USP, v. 15, n. especial, p. 93-108, 2008.

DANGAYACH, G. S.; DESHMUKH, S. G. An exploratory study of manufacturing strategy practices of machinery manufacturing companies in India. Omega, v. 34, p. 254-273, 2006. http://dx.doi.org/10.1016/j. omega.2004.10.009

DEMETER, K.; GELEl, A.; JENEl, l. The effect of strategy on supply chain configuration and management practices on the basis of two supply chains in the Hungarian automotive industry. International Journal of Production Economics, v. 104, p. 555-570, 2006. http://dx.doi. org/10.1016/j.jppe.2006.05.002

FOLTZ, C. B. Why users (fail to) read computer usage policies. Industrial Management \& Data Systems, v. 108, n. 6, 701-12, 2008. http://dx.doi. org/10.1108/02635570810883969

GARVIN, D. A. Manufacturing strategic planning. California Management Review, p. 85-106, 1993.

GAVIRA, M. 0. Gestão de inovações em subsidiárias de multinacionais do setor eletroeletrônico instaladas no Brasil. 2008. Tese (Doutorado em Política Científica e Tecnológica)-Universidade Estadual de Campinas, Campinas, 2008.

HAIR JUNIOR, J. F. et al. Fundamentos de métodos de pesquisa em administração. Porto Alegre: Bookman, 2005.

HARLAND, C. Supply chain operational performance roles. Integrated Manufacturing Systems, v. 8, n. 2, p. 7098,1997.http://dx.doi.org/10.1108/09576069710165756

HAUSER, G. et al. A indústria eletrônica no Brasil e na China: um estudo comparativo e a análise das políticas públicas de estímulo a capacidade tecnológica do setor. Journal of Technology Management \& Innovation, v. 2, n. 3, p. 85-96, 2007.

HSU. C. C. et al. Supply chain management practices as a mediator of the relationship between operations capability and firm performance. International Journal of Production Research, v. 47, n. 3, p. 835-855, 2009. http://dx.doi.org/10.1080/00207540701452142

JABBOUR, A. B. L. S. Prioridades competitivas da produção e práticas de gestão da cadeia de suprimentos: uma survey no setor eletroeletrônico brasileiro. 2009. Tese (Doutorado em Engenharia de Produção)-Universidade Federal de São Carlos, São Carlos, 2009.

KIM, J. S.; ARNOLD, P. Operationalizing manufacturing strategy - an exploratory study of constructs and linkage. International Journal of Operations \& Production Management, v. 16, n. 12, p. 45-73, 1996. http://dx.doi. org/10.1108/01443579610151751

$\mathrm{KOH}$, S. S. et al. The impact of supply chain management practices on performance of SMES. Industrial Management \& Data Systems, v. 107, n. 1, p. 103-124, 2007. http:// dx.doi.org/10.1108/02635570710719089
KRONMEYER FILHO, O. R.; FACHINELLO, T.; KLIEMANN NETO, F. J. 0 mapeamento da cadeia eletrônica no RS: um estudo inicial. In: ENCONTRO NACIONAL DE ENGENHARIA DE PRODUÇÃO - ENEGEP, 24., 2004, Florianópolis. Anais... ABEPRO, 2004.

LAMBERT, D. M.; COOPER, M. C. Issues in supply chain management. Industrial Marketing Management, v. 29, p. 65-83, 2000. http://dx.doi.org/10.1016/S00198501(99)00113-3

LAMBERT, D. M.; COOPER, M. C; PAGH, J. D. Supply chain management: implementation issues and research opportunities. The International Journal of Logistics Management, v. 9, n 2, p. 1-19, 1998. http://dx.doi. org/10.1108/09574099810805807

$\mathrm{Ll}$, S. et al. The impact of supply chain management practices on competitive advantage and organizational performance. Omega, v. 34, p. 107-124, 2006. http:// dx.doi.org/10.1016/j.omega.2004.08.002

$\mathrm{Ll}$, S. et al. Development and validation of a measurement instrument for studying supply chain management practices. Journal of Operations Management, v. 23, p. 618-641, 2005. http://dx.doi.org/10.1016/j. jom.2005.01.002

LUMMUS, R. R.; VOKURKA, R. J. Defining supply chain management: a historical perspective and practical guidelines. Industrial Management \& Data System, v. 99, n.1, p. 11-17, 1999. http://dx.doi. org/10.1108/02635579910243851

MAIA, J. L.; CERRA, A. L.; ALVES FILHO, A. G. Inter-relações entre estratégia de operações e gestão da cadeia de suprimentos: estudos de caso no segmento de motores para automóveis. Gestão \& Produção, v. 12, n. 3, p. 377-391, 2005.

MALHOTRA, M. K.; GROVER, V. An assessment of survey research in POM: from constructs to theory. Journal of Operations Management, v. 16, n. 4, p. 407-425, 1998. http://dx.doi.org/10.1016/S0272-6963(98)00021-7

MARTIN, P. R.; PATTERSON, J. W. On measuring company performance within a supply chain. International Journal of Production Research, v. 47, n. 9, p. 2449-2460, 2009. http://dx.doi.org/10.1080/00207540701725604

MARTÍN-PEÑA, M. L.; DÍAZ-GARRIDO, E. A taxonomy of manufacturing strategies in Spanish companies. International Journal of Operations \& Production Management, v. 28, n. 5, p. 455-477, 2008. http:// dx.doi.org/10.1108/01443570810867204

MELNYK, S. A. et al. Mapping the future of supply chain management: a Delphi study. International Journal of Productions Research, v. 5, p. 1-25, 2008.

MENTZER, J. T. et al. Defining supply chain management. Journal of Business Logistics, v. 22, n. 2, p. 1-25, 2001. http://dx.doi.org/10.1002/j.2158-1592.2001.tb00001.x

MOURITSEN, J.; SKJOTT-LARSEN, T.; KOTZAB, H. Exploring the contours of supply chain management. Integrated Manufacturing Systems, v. 14, n. 8, p. 686-695, 2003. http://dx.doi.org/10.1108/09576060310503483

NASSIF, A. Complexo eletrônico brasileiro. BNDES, 2002. BNDES 50 anos: histórias setoriais. Disponivel em: <www.bndespar.com.br>. Acesso em: 17 out. 2009.

OLHAGER, J.; SELLDIN, E. Supply chain management survey of Swedish manufacturing firms. International Journal of Production Economics, v. 89, p. 353-361, 2004. http:// dx.doi.org/10.1016/S0925-5273(03)00029-X 
PIRES, S. R. I. Gestão da cadeia de suprimentos (supply chain management) - conceitos, estratégias, práticas e casos. São Paulo: Atlas, 2004.

PIRES, S. R. 1; SACOMANO NETO, M. Características estruturais, relacionais e gerenciais na cadeia de suprimentos de um condomínio industrial na indústria automobilística. Produção, v. 20, n. 2, p. 172-185, 2010. http://dx.doi.org/10.1590/S0103-65132010005000032

PRAMATARI, K. Collaborative supply chain practices and evolving technological approaches. Supply Chain Management: An International Journal, v. 12, n. 3, p. 210-220, 2007. http://dx.doi. org/10.1108/13598540710742527

ROBB, D. J.; XIE, B.; ARTHANARI, T. Supply chain and operations practice and performance in Chinese furniture manufacturing. International Journal of Production Economics, v. 112, p. 683-699, 2008. http://dx.doi. org/10.1016/j.ijpe.2007.04.011

RUDBERG, M.; OLHAGER, J. Manufacturing networks and supply chains: an operations strategy perspective. Omega, v. 31, p. 29-39, 2003. http://dx.doi.org/10.1016/ S0305-0483(02)00063-4

SALLES, J. A. A. et al. Manufacturing strategies in the auto industry in Brazil and Spain. International Conference on Industrial Engineering and Engineering Management, v. 5674592, p. 1661-1665, 2010.

SEBRAE. Critérios e conceitos para classificação de empresas. Disponível em: <http://www.sebrae.com.br/ customizado/estudos-epesquisas/integra_bia?ident_ unico=97>. Acesso em: 12 mai. 2009.

SKINNER, W. Manufacturing-missing link in corporate strategy. Harvard Business Review, p. 136-145, 1969.

SLACK, N.; LEWIS, M. Operations Strategy. New Jersey: Prentice Hall, 2003.

SOSIK, J. J.; KAHAI, S. S.; PIOVOSO, M. J. Silver bullet or voodoo statistics?: A primer for using least squares data analytic technique in group and organization research. Group \& Organization Management, v. 35, n. 5, p. 5-36, 2009. http://dx.doi.org/10.1177/1059601108329198

SPENS, K.; WISNER, J. A study of supply chain management practices in Finland and the United States. Operations and Supply Chain Management, v. 2, n. 2. p. 79-92, 2009.

SYNODINOS, N. E. The "art" of questionnaire construction: some important considerations for manufacturing studies. Integrated Manufacturing Systems, v. 14, n. 3, p. 221-237, 2003. http://dx.doi. org/10.1108/09576060310463172

TAN, K. C. Supply chain management: practices, concerns, and performance issues. Journal of Supply Chain Management, v. 38, n. 1, p. 42-53, 2002. http://dx.doi. org/10.1111/j.1745-493X.2002.tb00119.x
TAN, K. C.; LYMAN, S. B.; WISNER, J. D. Supply chain management: a strategic perspective. International Journal of Operations \& Productions Management, v. 22, n. 6, p. 614-631, 2002. http://dx.doi. org/10.1108/01443570210427659

TAN, L.-T.; HWANG, A. R. Imported technology and R\&D in the Taiwanese electronic industry. Review of Development Economics, v. 6, n. 1, p. 77-90, 2002. http://dx.doi.org/10.1111/1467-9361.00142

URGAL-GONZÁLEZ, B.; GARCíA-VÁZQUEZ, J. M. The strategic influence of structural manufacturing decisions. International Journal of Operations \& Production Management, v. 27, n. 6, p. 605-626, 2007. http:// dx.doi.org/10.1108/01443570710750286

VAART, T.; DONK, D. P. A critical review of survey-based research in supply chain integration. International Journal of Production Economics, v. 111, p. 42-55, 2008. http://dx.doi.org/10.1016/j.ijpe.2006.10.011

VACHON, S.; HALLEY, A.; BEAULIEU, M. Aligning competitive priorities in the supply chain: the role of interactions with suppliers. International Journal of Operations \& Production Management, v. 29, n. 4, p. 322-344, 2009. http://dx.doi.org/10.1108/01443570910945800

VOKURKA, R. J.; DAVIS, R. A. Manufacturing strategy facility types. Industrial Management \& Data Systems, v. 104, n. 6, p. 490-504, 2004. http://dx.doi. org/10.1108/02635570410543799

VOSS, C. A. Alternative paradigms for manufacturing strategy. International Journal of Operations \& Production Management, v. 15, n. 4, p. 5-16, 1995. http://dx.doi. org/10.1108/01443579510083587

WANG, J.; CAO, D. Relationships between two approaches for planning manufacturing strategy: a strategic approach and a paradigmatic approach. International Journal of Production Economics, v. 115, p. 349-361, 2008. http:// dx.doi.org/10.1016/j.ijpe.2008.04.014

WARD, T. P.; DURAY, R. Manufacturing strategy in context: environment, competitive strategy and manufacturing strategy. Journal of Operations Management, v. 18, p. 123-138, 2000. http://dx.doi.org/10.1016/S02726963(99)00021-2

ZHAO, X.; LEE, T. Developments and emerging research opportunities in operations strategy and supply chain management. International Journal of production Economics, v. 120, p. 1-4, 2009. http://dx.doi. org/10.1016/j.ijpe.2008.12.010

ZHOU, H.; BENTON JUNIOR, W. C. Supply chain practice and information sharing. Journal of Operations Management, v. 25 , p. 1348-1365, 2007. http://dx.doi.org/10.1016/j. jom.2007.01.009 


\title{
Supply chain management practices and their possible relationships with manufacturing competitive priorities: empirical evidence from electro-electronic industry in light of Structural Equation Modeling
}

\begin{abstract}
This article aims to identify the supply chain management practices adopted in the Brazilian electronics sector and verify whether manufacturing competitive priorities of companies in this sector relate to the adoption of such practices. An empirical quantitative research was developed based on an e-mail survey with managers of companies in the electronics sector associated with the Brazilian Association of Electrical and Electronics Industry. Descriptive and multivariate statistical techniques of second generation (Structural Equation Modeling) were used to analyze the data. Main results showed that: (a) the supply chain management practices most deployed are focused on the integration and support of product development activities with customers; and (b) no significant relationships between competitive priorities and supply chain management practices were found.
\end{abstract}

\section{Keywords}

Supply chain practices. Competitive priorities. Electronic sector.

Apêndice 1.

\begin{tabular}{|c|c|}
\hline Constructo & Variáveis \\
\hline COM_P & $\begin{array}{l}\text { V1CP - Menor preço } \\
\text { V2CP - Funcionalidade } \\
\text { V3CP - Novo produto } \\
\text { V4CP - Menor tempo } \\
\text { V5CP - Gama produto } \\
\text { V6CP - Produto durável } \\
\text { V7CP - Custo produção } \\
\text { V8CP - Atender data entrega } \\
\text { V9CP - Volume produção } \\
\text { V10CP - Seguir requisito técnico } \\
\text { V11CP - Variedade produto } \\
\text { V12CP - Mudança rápida projeto } \\
\text { V13CP - Prevenir defeito }\end{array}$ \\
\hline SCM_P & $\begin{array}{l}\text { V1SCM - Integração cliente } \\
\text { V2SCM - Integração fornecedor } \\
\text { V3SCM - Envolvimento cliente planos } \\
\text { V4SCM - Envolvimento fornecedor planos } \\
\text { V5SCM - Colaboração fornecedor previsão demanda } \\
\text { V6SCM- Colaboração cliente previsão demanda } \\
\text { V7SCM - Colaboração fornecedor planejamento estoque } \\
\text { V8SCM - Colaboração cliente planejamento estoque } \\
\text { V9SCM - Colaboração fornecedor planejamento produção } \\
\text { V10SCM - Colaboração cliente planejamento produção } \\
\text { V11SCM - Criação equipes multifuncionais } \\
\text { V12SCM - Compartilhamento informação custo cliente } \\
\text { V13SCM - Compartilhamento informação lançamento produto fornecedor } \\
\text { V14SCM - Participação marketing cliente } \\
\text { V15SCM - Necessidade futura cliente } \\
\text { V16SCM - Comunicação fornecedor estratégia futura } \\
\text { V17SCM - Feedback cliente } \\
\text { V18SCM - Apoio decisão cliente novo produto } \\
\text { V19SCM - Consulta cliente programação produção } \\
\text { V20SCM - Consulta fornecedor programação produção } \\
\text { V21SCM - Apoio fornecedor desenvolvimento produto } \\
\text { V22SCM - Montagem próximo cliente }\end{array}$ \\
\hline
\end{tabular}

